\title{
The decision making process of being palliative volunteer
}

\author{
Ni Putu Wulan Purnama Sari ${ }^{1}$, Nia Novita Sari ${ }^{2}$ \\ ${ }^{1}$ Department of Palliative Nursing, Faculty of Nursing, Widya Mandala Catholic University Surabaya, Indonesia \\ ${ }^{2}$ Department of Basic Nursing \& Management, Faculty of Nursing, Widya Mandala Catholic University Surabaya, \\ Indonesia
}

\begin{tabular}{l} 
Article Info \\
\hline Article history: \\
Received Mar 19, 2019 \\
Revised Apr 19, 2019 \\
Accepted May 23, 2019 \\
\hline
\end{tabular}

\section{Keywords:}

Community

Decision making

Palliative

Palliative volunteer

Volunteer

\begin{abstract}
Palliative care delivery in Surabaya community, Indonesia, is in collaboration with palliative volunteers. The decision to be palliative volunteer was not easy, mainly because of financial matter, time limitation, and role conflict. This study aimed to analyze the decision making process of being a palliative volunteer in Surabaya. This qualitative study involved 13 female palliative volunteers under the supervision of Public Health Center (PHC) of Rangkah. In-depth-interview was used for data collection. Instruments used were interview guideline, observation sheet, and voice recorder. Collaizi method was used for data analysis. The majority was 40-50 years old, married, housewife, and high school graduated. Each participant manages 5-8 patients to be home-visited regularly. The driving force and the reason to persistently be a palliative volunteer was the willingness to help others in need. The major entry point acting as stimulus was health care professional in the Rangkah PHC. The decision making model applied was descriptive model, because despite of insufficient information through various entry points but the decision made was fast and persistent.
\end{abstract}

Copyright $@ 2019$ Institute of Advanced Engineering and Science. All rights reserved.

\section{Corresponding Author:}

Ni Putu Wulan Purnama Sari,

Department of Palliative Nursing, Faculty of Nursing,

Widya Mandala Catholic University Surabaya,

Jl. Raya Kalisari Selatan 1, Pakuwon City, Surabaya 60112, Indonesia.

Email: wulanpurnama@ukwms.ac.id

\section{INTRODUCTION}

Palliative care is an approach aimed at improving the quality of life of patients and families facing problems related to life-threatening illnesses, through prevention and elimination of suffering, early identification and orderly assessment, and management of pain and other problems, include physical, psychosocial and spiritual problems (Decree of Ministry of Health, Republic of Indonesia, No. 812/Menkes/SK/VII/2007) [1]. Palliative care was originally intended for cancer patients, but now the scope is widespread. Currently palliative care can also be accepted by people living with HIV/AIDS, terminal illness and other kind of illness in which the patients require intensive treatment of symptoms [2]. Nowadays, the use of palliative services is on the raise because of the trend of aging population worldwide (3). Two third of those in need of palliative care are in the low or middle income countries [4]. The main purpose of providing palliative care to these patients is not only to help them to relieve/alleviate their suffering and improve their quality of life, but also for improving their family's quality of life [1]. Palliative care could be delivered in clinical/hospital and community context. An evaluative study towards palliative care delivery in community context in Busan, Korea, found that the quality of life of the patients improved by providing services at an appropriate level and by raising the recognition of palliative care in the community [5].

In health sector, palliative cares are the emerging model of integrated practice [6]. In order to improve the quality of life of patients and their family in community context, community nurse in the Public 
Health Centre (PHC) does not work alone. Optimal interdisciplinary collaboration through multi-professional teams in palliative care delivery system will facilitate the achievement of palliative care goals. In addition to health workers, one member of the multi-professional interdisciplinary team is palliative volunteers [2], sometimes known as hospice volunteers or end of life volunteers. Palliative volunteers are groups of common people who volunteer to contribute their time, energy, thoughts and skills to help alleviate the suffering of palliative patients in the form of simple care activities; physical, psychological, or socially [7]. Most individuals volunteer for hospice following a death in their own life, many scholars assume that being motivated by past experiences with death means that individuals are seeking out hospice volunteering as a means for working through their own unresolved grief [8]. A study towards 10 hospice volunteers in Sweden found that volunteers need to be affirmed as a caring person and received in fellowship at the hospice, and they will feel rejected if their need for meaning and belonging to the hospice is not satisfied [9]. Therefore the PHC needs to set goals in terms of volunteer support, particularly regarding existential issues following the encounter of volunteers with the PHC and the patient/family. Another survey towards 290 UK adult hospices and specialist palliative care services involving volunteers showed that volunteers were most commonly involved in day care and pastoral/faith-based care services, and were involved in a wide range of activities, including sitting with dying patients [10].

The problems faced by palliative patients are often very complex because of the total suffering they experience. Their total suffering includes physical pain and other symptoms, psychological suffering e.g. stress/anxiety/depression, cultural suffering, social suffering, and spiritual suffering [1]. Most palliative patients think there is nothing more that can be done to achieve healing. This requires that volunteers be able to know the meaning of each patient's action and help them to overcome psychological, social, and cultural problems; volunteer activity also guides the patients spiritually [7]. Palliative volunteers are often considered as a trusted confidant; therefore they are in a unique position to provide spiritual care, especially in dealing with patient's guilt, regret, and forgiveness [11]. Biological aspects are usually handled by doctors and nurses, while psychological, social, cultural and spiritual aspects are often handled by volunteers. This causes $25 \%$ of the volunteer's job to be a "psychologist" in the community [7].

Surabaya is the birthplace of palliative care in Indonesia, and even the Mayor of Surabaya declared this city as a palliative city in 2010 marked by the inauguration of a big palliative garden right in the heart of the city. At the Public Health Centre (PHC) setting in Surabaya, there are some PHCs which already fostered the palliative volunteer group, until they exists with a mature annual work program under the supervision of respectable PHC. The result of preliminary study at PHC of Rangkah, Surabaya, showed that the first palliative volunteer recruitment was conducted in 2009. At that time, there were \pm 50 individuals, mostly female (housewife), who enrolled and attended palliative volunteer training in Dr. Soetomo Public Hospital, Surabaya. In 2016, there were only 15 active volunteers remained. It means in 7 years (2009-2016), 35 volunteers were quit because of various reasons (70\%). Natural selection causes many volunteers to quit, possibly due to financial matter, time limitation, and role conflict. A study towards 81 hospice volunteers in South Carolina showed that one of the factor influencing difficult retention of hospice volunteers was psychological burnout; therefore ongoing volunteer and communication training, educational opportunities, the development and use of decision-making teams, and emotional support for the volunteers are needed [12].

Regarding financial matter, volunteers work without any salary. Voluntary work, as uncommodified work, can be distinguished from paid commodified work in that it is freely undertaken for no financial payment and is often motivated by altruism shaped by a sense of wanting to 'give back' to the community [13]. But, it is better to pay for their transport expenses related to home care activities. Practically, they cannot claim those transport expenses because there is no specific budget allocated for volunteer in PHC setting. The position of home care in palliative care services is very important because: a) It is the right thing to do for many of those we care for who are seriously ill. b) Family members were more satisfied with overall quality of care through home care, and c) The PHC needs to meet the accreditation standard of services [14]. Therefore, the claim of transport expense needs to be paid to ensure the continuity of home care activities by palliative volunteers; it is not the same with giving salary to the volunteers. Regarding time limitation, long term home-visiting is needed to build relationships of trust and genuine caring which considered as the ideal of our community nowadays. Another study towards 13 hospice volunteer coordinators in northwestern Ontario showed that most volunteers spent a large part of their time visiting medically frail and lonely elderly who are at risk of dying alone or without adequate companionship at the end of life [15]. Regarding role conflict, actually palliative volunteers inhabit a unique third culture of care that fuses elements of formal care with the informal visiting of friends and neighbours [16], but sometimes the high role demand in the volunteer's family, especially when the volunteer is the "mother," making the situation sometimes difficult to deal with volunteering [17]. Regarding psychological burnout, a study towards 15 palliative volunteers showed that there are various stressors (difficult situation) 
experienced by hospice volunteers contributing to burnout: a) Issues related to hospice work, such as: dealing directly with patients, dealing with patient's family members, and dealing with death and dying, and b) Personal issues, such as: not enough time, personal fears, and personnel challenges [17].

The high quality of palliative care delivery at home in community context depends on the active participation of various parties, one of which is the active involvement of palliative volunteers. Palliative volunteers bridge the relationship between health care professionals in the PHC and the patients/family in the community. A study towards 32 community volunteer workers in Uganda showed that volunteers acted as a bridge to the hospice in identifying patients; they had positive impact on patients, families, and the hospice team [18]. Recruitment and retention of palliative volunteers is an important point for maintaining their existence. In fact, the retention of palliative volunteers is difficult because of various factors. The decision-making process and the persistence to be palliative volunteers need to be further investigated to get an overview of their condition/situation, and to develop a prospective solution to be implemented in the near future to maintain the amount and performance of palliative volunteers.

This study aimed to analyze the decision making process and the persistence of the common people to become a palliative volunteer. The study focus was examined in seven aspects, which include: a) Initial perception. b) Internal motivation. c) Vision and mission. d) Social support. e) Influencing factors and decision-making steps. f) Volunteer education program/training, and g) The duties and obligations of palliative volunteers.

\section{RESEARCH METHOD}

This hermeneutic phenomenological study involved 13 participants. The study population was all palliative volunteers in Surabaya, Indonesia. Affordable population was all palliative volunteers under the supervision of Rangkah PHC. Purposive sampling was used for selecting participants. Participant was the volunteer who works in the working area of Rangkah, Gading, and Pacar Keling PHC, and met the sample criteria. Sample criteria were consisted of inclusion and exclusion criteria. Inclusion criteria consisted of: a) Cooperative. b) Manage good communication using Bahasa Indonesia. c) Being able to express her opinion in a good way. d) Willing to participate in the study as long as needed. e) Providing enough time for the interview. f) Giving direct service to the patients/family by doing home visit, and g) Classy enough to be familiar with researcher that it was more interesting to be used as informants. Exclusion criteria consisted of: a) Speaking difficulties, and b) Being hospitalized.

The interview was conducted at the volunteer's residence. Data were collected in September 2017. Prior to data collection process, this study protocol has been reviewed by the Institute of Research and Community Development of Widya Mandala Catholic University Surabaya, and informed consent preceded participation. Data collection technique was in-depth interviews recorded by a voice recorder, and then transcribed verbatim. The questions addressed were semi-structured open ended questions about the decision making process and the experience of being a palliative volunteer. Researcher and participants had the flexibility to improvise and be creative in expressing the research problem from a personal point of view. Improvised questions were tailored to the spontaneous feedback / answers of each participant. Data retrieval continued until no new information added, or information saturation has occurred. Interview guideline was made based on seven aspect aspects, namely: a) Initial perception. b) Internal motivation. c) Vision and mission. d) Social support, e) Influencing factors and decision-making steps. f) Volunteer education program/training, and g) The duties and obligations of palliative volunteers. Data analysis was done by nine steps of Collaizi method [19], namely: a) Describe the phenomenon under study through literature study, b) Collect descriptions of phenomena through interviews and write them in verbatim form, c) Read the entire description of the phenomenon that has been submitted by participants two to three times thoroughly until the researchers feel able to understand the life experience of the informant, d) Re-read transcripts of interview results (verbatim) and cite meaningful statements, e) Describe the meaning in a significant statement to find the keywords that are being the core of the statement, f) Organize various sets of meaning formulated into theme groups, g) Construct a theme found during the data analysis process and write it down into a deep description, h) Reunite informant to validate the description that has been compiled, and i) Combine validation data into full and in-depth descriptions of research reports so readers are able to understand the informant's life experiences. The data validation method (triangulation) used was communicative validity by re-confirming collected data and description back to the participants. The results of this study could be transferred into social situations or similar phenomena which is similar to this study context. 


\section{RESULTS AND DISCUSSION}

The Palliative Volunteer Association under the supervision of Rangkah PHC is an integration of palliative volunteer who works in the working area of Rangkah, Gading, and Pacar Keling PHC, Surabaya. Its member in September 2017 was 30 woman, some are not active in volunteer activities. The assignment of volunteers to do home visit and execute their work program in community context is coordinated by the Head of the Rangkah PHC via her delegation to the volunteer coordinator. Every month the volunteers hold regular coordination meeting to discuss monthly work programs and find solutions to problems encountered in the field during home visit. Volunteers are required to make monthly reports on home visit results. In addition to home visit, it is common for volunteers to be the source of case findings in the field, especially the patients who have not been reached by the PHC. Sources of information are usually locals. The number of managed patients between each volunteer is different due to the volunteer's flying hours, their readiness, and the severity of the disease or the complexity of the patient's care/problems.

Participants in this study amounted to 13 volunteers (43.3\% among all), $100 \%$ women. They are all active volunteers and often attend various palliative activities/events held by various parties (Rangkah PHC, Dr. Soetomo Public Hospital, the city government, etc.). One of the participants acted as the volunteer coordinator. Table 1 explains the demographic characteristic of participants in details.

Table 1. Demography characteristic $(n=13)$

\begin{tabular}{ccc}
\hline Characteristic & Frequency & $\%$ \\
\hline 1. Age $($ years old) & 0 & 0 \\
a. $<30$ & 2 & 15.38 \\
b. $>30-40$ & 6 & 46.15 \\
c. $>40-50$ & 2 & 15.38 \\
d. $>50-60$ & 3 & 23.08 \\
e. $>60$ & & \\
2. Marital status & 12 & 92.31 \\
a. Married & 1 & 7.69 \\
b. Widowed & & \\
3. Educational background & 2 & 15.38 \\
a. Elementary school & 2 & 15.38 \\
b. Secondary school & 8 & 61.54 \\
c. High school & 1 & 7.69 \\
d. University graduates & & \\
4. Occupation & 3 & 23.08 \\
a. Retire & 10 & 76.92 \\
b. Housewife & & \\
5. Patient in charge & 3 & 23.08 \\
a. <5 & 7 & 53.85 \\
b. 5-8 & 3 & 23.08 \\
c. 9-12 & &
\end{tabular}

The results showed that the majority were $>40-50$ years old $(46.15 \%)$, married $(92.31 \%)$, high school graduates $(61.54 \%)$, housewife $(76.92 \%)$, and manage 5-8 patients $(53.85 \%)$. Based on interview result, the majority firstly heard the term of palliative volunteer was in 2008 (30.77\%), 2013-2016 (30.77\%), and $30.77 \%$ admitted forgot. This term was first heard at a volunteer recruitment event organized by Rangkah PHC (53.85\%), volunteer training (30.77\%), seminar and reunion events (@ 7.69\%). The generated theme was categorized based on seven variables of this study focus.

\subsection{Initial perception}

There are six themes generated regarding the initial perception of volunteers after hearing the term of palliative volunteer, consist of: a) The duty is to assist the patients. b) A social work. c) Must join a training, d) Frequent interaction with cancer patients, e) Have many duties, and f) High exposures to other's sufferings. Below are few statements supporting the study findings.

What is on my mind is a person who is willing to serve the sick (I. 03)

What I thought is I want to help others who have cancer (I. O8)

My perception is a person who is willing to help the patients who really need helps (I. 09)

Other than that, researcher also asked about their initial perception about the duties and obligations by being a palliative volunteer: 11 themes were generated, namely: a) Assist the patients. b) Motivate the patients. c) Home visit. d) Give simple care. e) Accompany the patients. f) Being the source of information. g) Entertaining the patients. h) Being a supervisor in drug administration. i Work unconditionally,

Int. J. Public Health Sci. Vol. 8, No. 2, June 2019: 263 - 276 
j) Bridging the patients and health professionals relationship, and k) Register the patient. Below are few statements supporting the study findings.

In my mind, the duty and obligation is not only doing home visit but also giving simple care and motivating them (I. 04)

The duties are: a) Home visit. b) Accompanying and motivating the patients by entertaining them for reducing the pain. c) Remind the patients to consume medication, eat nutritious food, and drink the milk gained from the PHC (I. 05)

In my mind, the duties are: a) Register the patients in my area. 2) Give the exact and responsible information to them and their families about the disease, especially the prevention and management of cancer, and c) Motivate the patients so they become obedient to the medication regiment (I. 13)

In addition, researcher asked about the first impression when first time served as a palliative volunteer. There are seven themes generated, namely: a) Feeling pitiful towards the patients. b) Feeling happy because can help the patients. c) Feeling relieved after alleviating other's suffering. d) Feeling scared after seeing the patient's condition. e) Feeling proud because manage to help the patients. f) Feeling moved when seeing the patient's suffering, and g) No impression. Below are few statements supporting the study findings.

First time I felt so scared, especially when I saw the breast cancer patient with a wound that already hollow and purulent, I felt pitiful on her, I suggested her to join the legio and she agreed, then she became a volunteer also. She was a nurse from a private hospital in Surabaya. I accompanied her, doing home visit, until then she died peacefully (I. O3)

I felt very scared and pitiful when I saw such patient's condition (I. 06)

The unforgotten impression I had when I visited the patient for the first time is she thought that I was a physician. I felt so pitiful toward her when I accompanied her to the PHC and she said that she could not go with me because she had no money, even not a single Rupiah for took the trishaw, I paid for it and for the medicine also. I still feel like I want to cry every time I recall this memory (I.13)

Perception is the experience of the object or relationship obtained by summing up information and sending messages [20]. Perception gives meaning to sensory stimuli. Cognitive perceptual fields are always organized and given meaning by the individual. Perception is not determined by the type/form of the stimulus, but by individual characteristics that respond to the stimulus. There are two main factors that determine individual perceptions, namely functional factors (often called objective frameworks) and structural factors [21]. Functional factors derived from the needs (momentarily), mental readiness, emotional atmosphere, cultural background, past experience, including personal factors. Structural factors derived from the physical stimulation and nerve effects that are generated on the individual nervous system. Both of these factors are more directed to the needs and experiences experienced by the perceived individual through physical stimuli or senses towards a particular object. This study finding was supported by a study towards 10 hospice volunteers in Sweden [9]. They found that in the beginning participants realized that a hospice volunteer is someone who being assigned a constructive task and expected to have more contact with the patients. Volunteers contributed by performing a variety of tasks that were additional to or an enhancement of the work performed by the regular staff, including the inter-professional healthcare team.

The palliative volunteers who participated in the study were the majority of women aged $>40-50$ years old who were married, graduated from high school and worked as housewife. Personal factors such as needs (momentarily), mental readiness, emotional mood, cultural background, and past experiences cannot be equated, but can be the same at a point where they interact as fellow volunteers. The experience of dealing with palliative patients also cannot be equated with their flight hours as volunteers, but an understanding of the tasks and obligations that make enough participants to live their role as a volunteer pretty well. In addition, supervision and guidance from local health officials will further homogenize the perception that emerged among volunteers about the meaning of the palliative concept, the duties and obligations of volunteers. Interpersonal communication and palliative events also need to be held to maintain the stimulus intensity of volunteers that form the ideal response desired by health professionals from the volunteers.

\subsection{Internal motivation}

Consistent with functional theorizing, most of the participants reported having more than one motive for enrolling as palliative volunteers. There are seven themes regarding the personal interest to become a palliative volunteer, namely: a) Close person has a cancer. b) Heart calling. c) The willing to help others. d) Self actualization. e) The willing to increase health knowledge. f) Love to join social work, and g) Chosen by health professional. Below are few statements supporting the study findings.

I want to become a volunteer because one of my families had liver cancer, and I want to help her so bad. I met a friend who already became a volunteer for years, she invited me to join the association, I agreed and I become a volunteer until now (I.09) 
I want to know further about cancer, and my heart is calling me to do this social work to be able to help others (I. 05)

After I experienced 3-days-training of palliative volunteer, I felt my heart calling me to become a volunteer. Other than that, I also become a cadre of palliative gymnastic (I. 11)

According to Semiawan, interest is a mental state that produces a directed response to a particular situation or object that pleases and gives individual satisfaction. Interest serves as a driving force or motivation that directs a person to perform a specific activity [22]. Stiggins states that the initial desire or interest is one dimension of the affective aspect that plays a role in one's life [23]. The affective aspect is the aspect that identifies the emotional dimensions of emotional awareness, disposition, and will that affect one's thoughts and actions.

Researcher also asked about the factors influencing the decision to become a palliative volunteer. Nine themes were generated regarding this. Below are few statements supporting the study findings.

The most influencing factor of me becoming a volunteer was the emerge feeling to help others in suffering. The most inner desire was alleviating the patient's suffering, although I entertained only, motivating them, gave the spirit and always pray for them (I.O1)

The most influencing factor for me was the willing to help others, and because I have joined Maria Legio for almost 25 years so I had no doubt when I took the decision (I. O1)

The most influencing factor for me is the willing to know how volunteer works; a strong desire to socialize (I. 06)

Motivation is the driving force within the individual that impels him to act which results from unfulfilled need [24]. There are two types of motivation: intrinsic and extrinsic motivation [25]. Intrinsic motivation is an active motive that does not need to be stimulated from the outside/environment because in each individual there is a drive/goal to get something. Extrinsic motivation is an active motive that functions because of the outside stimulation.

This study finding was supported by a study towards 57 palliative volunteers, especially in the management of HIV/AIDS in community context, which showed that most volunteers have more than one motive to be a volunteer. Of the 11 categories of motivations identified, those relating to altruistic concerns for others and community, employment or career benefits and a desire by the unemployed to avoid idleness were the most frequently mentioned [26]. Volunteers also saw volunteering as an opportunity to learn caring skills or to put their own skills to good use, for personal growth and to attract good things to themselves. A few of the volunteers were heeding a religious call, hoping to gain community recognition, dealing with a devastating experience of AIDS in the family or motivated for social reasons. Another study towards 10 hospice volunteers focusing on elderly with dementia also supported this study finding. It showed that most volunteers expressed a great deal of compassion satisfaction and meaning related to their volunteer work, and described feelings of love, joy, and happiness from their volunteering experiences [27]. A combined literature review showed that "to help ease the pain of those living with a life-threathening illness" was rated as the most influential reason/motive for becoming a palliative volunteer [28].

In this study, the internal motivation that emerged in participants was derived from the psychological discomfort after seeing the suffering of others. Needs that have not been fulfilled is the need for self-actualization which is then met through activities to help others to feel themselves useful to others. Self-actualization is the highest requirement in Maslow's hierarchy of needs, where this need can only be met if the four other types of needs beneath are met. Based on the age of participants, it appears that the task of development at that age has begun to take place; it is getting closer to God or increasing spiritual activity. Participants express it through the desire to earn reward in afterlife.

\subsection{Vision and mission}

There are seven themes generated regarding the vision and mission of common people becoming a palliative volunteer, namely: a) To help others. b) To motivate the patients. c) To alleviate the patient's suffering, d) Indonesia free from cancer. e) To accompany the patients. f) To give comfort to the patients. and g) To bridge the relationship between the patients and health professionals. Below are few statements supporting the study findings.

My vision and mission is to help others, to alleviate their sufferings, especially in cancer patients is to reduce the pain (I.02)

My vision is to pleases the patients, my mission is I do really want to pleases the patients, give them the spirit, so they could feel sincere with God's will and they have great hope to be healed (I.04)

I want to help others, especially cancer patients, and as a volunteer I want our country to be free from cancer (I.08)

Vision is a series of sentences that express the ideals/dreams of individuals/organizations/companies to be achieved in the future [29]. Vision is a picture that challenges the desired future state. 
Vision is useful for: a) Unifying goals, directions, and objectives. b) Becoming the basis for resource use, allocation, and control. c) Shaping and building culture. Mission is a series of sentences that state the purpose/reason of existence that contains what is provided for the community; it could be a product/service. Mission is the purpose and the reason that gives the direction as well as the boundary of the process of achieving the goal. Mission is the stage of action that will be implemented from the existed vision to achieve the goal.

This study finding was supported by a study towards 114 volunteers who were interviewed in three work settings: palliative care units, mobile palliative care teams, and traditional services. They found that volunteers explained they "are there" not "to do", but just "to be there out of human solidarity". The volunteers" viewpoint was "being there to be there". Indeed, they described the palliative care model and their missions in quite similar terms: "represent civil society to show these people that we are not abandoning them", "ensure a presence and a willingness to listen", "make oneself useful", "do things in a humane way for the person", and "be there to be there" [30].

In this study, the vision and mission of the participants when they play a role as palliative volunteer was related to their routine tasks and obligations. There were only two participants (15.38\%) who have a vision conceptually; it is Indonesia free from cancer. It seemed that the majority have not understood the vision and mission as volunteer. Participants need to share their personal vision and mission and then create an organizational vision and mission, so that they could ultimately achieve their goals. Results showed that $53.85 \%$ participants persistently become a palliative volunteer because of the good will to help others in need. Below are few statements supporting the study findings.

The reason is simple, I just want to help. As long as I feel physically strong, I will still be a volunteer. As long as there are people like the cancer patients who need help, then I will be there to help. (I.O2)

I just want to help others who in need of it. (I.08)

I want to help the palliative patients and give them motivation so that nobody feels hopeless. (I.09)

The stagnant behavior of the participants is shown by staying active as a volunteer until now despite of all the existing limitations (not paid, no transport money, high reliance of the patients/family, high demand from the related to implementation of work program and report, multi-task in the household, etc.) potential caused by behavioral resistance. Before a person adopts a new behavior, in that person will occur sequential process starting from a) Awareness, the subject is aware of the existence of the stimulus. b) Interest, subject interested in stimulus. c) Evaluation, subjects weighing either good or bad stimulus. d) Trial, subjects try new behavior and e) Adoption, new behaved subjects according to knowledge, awareness, and attitudes toward stimulus [31]. The process of achieving the adoption of new behavior depends on the process of behavioral change being attempted, and it can take place sooner or later. If the process through coercion, the adoption is usually fast; but if the process through education (learning) or persuasive, then the adoption will be slowly but it is usually more difficult to change (resistant) [32]. Introduces new determinants of the pace of adoption of new behaviors, namely: a) The nature of behavioral innovation. b) Promotional activities undertaken, c) The characteristic of the social system in the society, and d) The type of decision-making [31].

Participant's behavioral resistance to remain as a palliative volunteer strongly reflects their self-integrity and the stability of early decision making. This happens cannot be separated from the formation of a very positive attitude among volunteers about the profession itself, especially related to the duties and obligations. Attitudes include three main elements, namely: a) The object of attitude (self-defined by the individual). b) A set of values or beliefs held by the individual toward the object of attitude, and c) The tendency to act. Another important dimension of attitude is the level of knowledge and strength of attitudes or resistance to change. If the intensity of attitude is high then the attitude strength is also expected to be high. The strength of attitudes can be high if the level of knowledge is high. In some people it also can be found that attitude strength is high but the knowledge level is low. Attitude that is high in intensity and strength, as well as knowledge can be a predictor of behavior, but if only attitude alone is not enough to determine individual behavior. The positive attitude of volunteers toward her profession can determine her activeness in the regular activities. In addition to attitude, there are other factors that also could determine the resistance of this volunteer behavior, such as family/social support.

\subsection{Social support}

Participants revealed that there were six source of social support regarding their role as a volunteer. 69.23\% participants got social support from their own family, especially the husband and children. The rest got support from the volunteer leader, palliative patient, close friend, and religious activist in the church. Below are few statements supporting the study findings.

The one who support my decision was my children, because I have a late husband. (I.O1)

Initially it came from myself, then my husband and children supported this decision also after a while I play my new role as a volunteer. (I.02) 
I am myself, my husband and children also gave support. (I.05)

Social support is a picture of a supporter accessible to individuals through relationship with other individuals, groups, families and communities [33]. Social support is defined as information from others who are valued, and part of a communication network with parents, spouses or lovers, other relatives, social contacts, and the community [34]. Thus, social support is the availability of resources that provide physical and psychological comfort obtained through the interaction of individuals with others so that the individual feels loved, cared for, valued and part of a social group [35].

A study towards 79 palliative volunteers in Flanders, Belgium, showed that social support for palliative volunteers mostly come from nurses and psychologists who provided emotional and functional support; volunteers collaborate mostly with nurses, less with psychologists, but not with physicians [36]. Another study towards 39 end-of-life volunteers showed that communication, emotional support, education, advocacy, and personal fatigue as the most important challenges to be addressed through support interventions at the organizational level, from PHC for instance, via professional support, volunteer mentoring, and continuing education program) [37].

The majority of participants expressed that they got support/reinforcement of the decision taken to be a volunteer from their main families (spouse/children). The duties and obligations of volunteers often lead to a role conflict in volunteers who are mostly a housewife due to the high demands of household work and attentions needed by the other family members. Participants expressed if the family has supported them, then when the obligations of a housewife was somehow neglected/abandoned then the family will not complaint because they could realized that it was a consequence of the decision taken, especially if the level of volunteer activity is very high. The majority of volunteers have entered advanced adulthood stage (pre-elderly); it can be assumed that her children have entered at least early adulthood. Their children can be independent in taking care of their needs. The task of a housewife becomes lighter for the volunteers. Some participant's spouse are already passed away, so when their children are grown, their attention can be diverted to other more useful things, such as helping others. This reason was expressed several times by participants related to the initial perception, interest, the reasons to join, motivation to be persistent, and factors influencing her decision to become a palliative volunteer.

\subsection{Influencing factors and decision-making steps}

Results showed that there were eight entry points acting as the stimulus to the participants before they made the decision to be a palliative volunteer, namely: a) PHC authority. b) Health care professionals. c) Palliative events. d) Community cadre. e) Volunteer leader. f) Palliative patients. g) Friends, and h) Government officer. Below are few statements regarding the process of becoming a palliative volunteer in this study context.

It started from May 11, 2008 in Adi Guna Maternity Hospital. At that time, I got an invitation in which it was only one invitation for each district. I felt it was unbelievable, why me? Is it not wrong name on it? I did not understand about the invitation for being a palliative volunteer. Basically in the district level I was just a community cadre for children care. After I joined the palliative training I began to understand the concept of palliative care and what is a volunteer needed by the community, I started to think how great palliative volunteer is, and I was blessed if I could join the group of volunteer with a very noble task. (I.02)

I got an invitation to join palliative volunteer, there was an event in Adi guna Maternity Hospital. I have no idea at all, so I ask a doctor, the head of Pacar Keling PHC. He answered that in that event I will get training about terminally ill cancer patients. So my job is to motivate the patients so that they can accept their condition, they do not feel alienated. I should happily listen to what they felt, I will be the representative of Pacar Keling PHC officer in Pacar Kembang District. Then he said if the district authority agreed in the next two month there will be palliative care training, then PHC will send me as participant. Finally PHC and the district authority agreed to chose me, then I joined the training in May 2008. At the event finally I understand about palliate care. Since that, I become a member of palliative volunteer. (I.10)

This study finding was supported by a study towards nine volunteers in England which showed that how events can be used as networking and discussion between volunteers that may not usually have such opportunities to communicate with one another [38]. Hospice volunteer could be a key facilitator of public engagement in palliative care services, but approaches to their involvement require further development. Table 2 explains the joining process of becoming a palliative volunteer from each participant.

An integrated review study about factors affecting volunteering in palliative care showed that several interrelated factors play important role, in particular an increasingly aging population which includes an aging volunteer and health professional workforce, distance (geography), isolation, lack of privacy, limited health care services and infrastructure, workforce shortages, and psychosocial impact of end of life 
care in the community [39]. Another study towards 200 adults about decision making in uncertain conditions showed that no age differences in choice behavior under risk with a priori probabilities; if feedback is provided, older adults are less ambiguity averse than young adults, especially when feedback gives positive effect on the propensity to gamble in uncertain conditions [40].

Table 2. Joining process of becoming a palliative volunteer

\begin{tabular}{cl}
\hline Participant Code & Joining Process \\
\hline 02 & $\begin{array}{l}\text { Participated in a training } \rightarrow \text { joined the volunter group } \\
\text { Got invitation } \rightarrow \text { participated in a training } \rightarrow \text { joined the volunteer group } \\
\text { Health care professional approached the religious leader } \rightarrow \text { the religious leader } \\
\text { persuaded the member of spiritual group } \rightarrow \text { accepted the offer } \rightarrow \text { joined the } \\
\text { volunteer group } \\
\text { Appointed by local cadre } \rightarrow \text { accepted the offer } \rightarrow \text { joined the volunteer group } \\
\text { Participated in a palliative event } \rightarrow \text { got an offer } \rightarrow \text { accepted the offer } \rightarrow \text { joined the } \\
\text { volunteer group } \\
\text { The volunteer leader persuaded } \rightarrow \text { accepted the offer } \rightarrow \text { joined the volunteer group }\end{array}$ \\
05 & $\begin{array}{l}\text { Health care professional invited to join a home visit } \rightarrow \text { participated in some home } \\
\text { visits } \rightarrow \text { recruited by the PHC } \rightarrow \text { joined the volunteer group }\end{array}$ \\
06 & $\begin{array}{l}\text { Saw the patient's condition and sufferings } \rightarrow \text { the heart called } \rightarrow \text { motivated to join } \\
\text { ingined the volunteer group }\end{array}$ \\
08 & $\begin{array}{l}\text { Invited by a friend } \rightarrow \text { accepted the offer } \rightarrow \text { joined the volunteer group } \\
\text { recruited by the PHC and the local authority } \rightarrow \text { participated in a training } \rightarrow \text { joined } \\
\text { the volunteer group } \\
\text { Got an invitation } \rightarrow \text { participated in a training } \rightarrow \text { joined the volunteer group } \\
\text { The head of PHC persuaded } \rightarrow \text { got interested } \rightarrow \text { joined the volunteer group } \\
\text { Got an invitation } \rightarrow \text { participated in a training } \rightarrow \text { joined the volunteer group }\end{array}$ \\
10 &
\end{tabular}

Results showed that there were various entry points acted as a stimulus for the common people to join the group of palliative volunteer, mostly were from the health care professional who works in the PHC itself $(53.85 \%)$, the remaining was palliative event, cadre, volunteer leader, patients, friends, and local authority. The behavioral theory of Skinner suggests that behavior is a person's response to a stimulus, often described by S-O-R or Stimulus-Organism-Response [32]. Based on Figure 1, the researcher made an approach to the process of being a palliative volunteer using Skinner's theory. In the study context, the stimulus is the entry point of information about palliative, organism is a new role adaptation that occurs to volunteers passing through internal processes, and the response is the implementation of volunteer new role. Figure 1 showed that after certain exposures to any kind of entry point, the individual starts to adapt the new role by accepting the offer to be a volunteer, learning process through palliative care training, increasing the knowledge about palliative concept and its delivery in community context, feeling motivated to implement the new role, and increasing skills during the process of new role implementation.

The model of decision making applied by the participants in this study was descriptive model. This model was applicable to participants because the decision-making stage to become a palliative volunteer based on incomplete information from various entry points in Figure 1, and even some participants have not participated in any volunteer training before deciding to become a palliative volunteer. The information gained at the beginning was lacking because of time constraints, financial issue, or other problem. There are several other factors that influence the implementation of this fast and premature decision. These factors could be further studied in the participants who has attended the volunteer training but did not decide to become a volunteer in the end. 


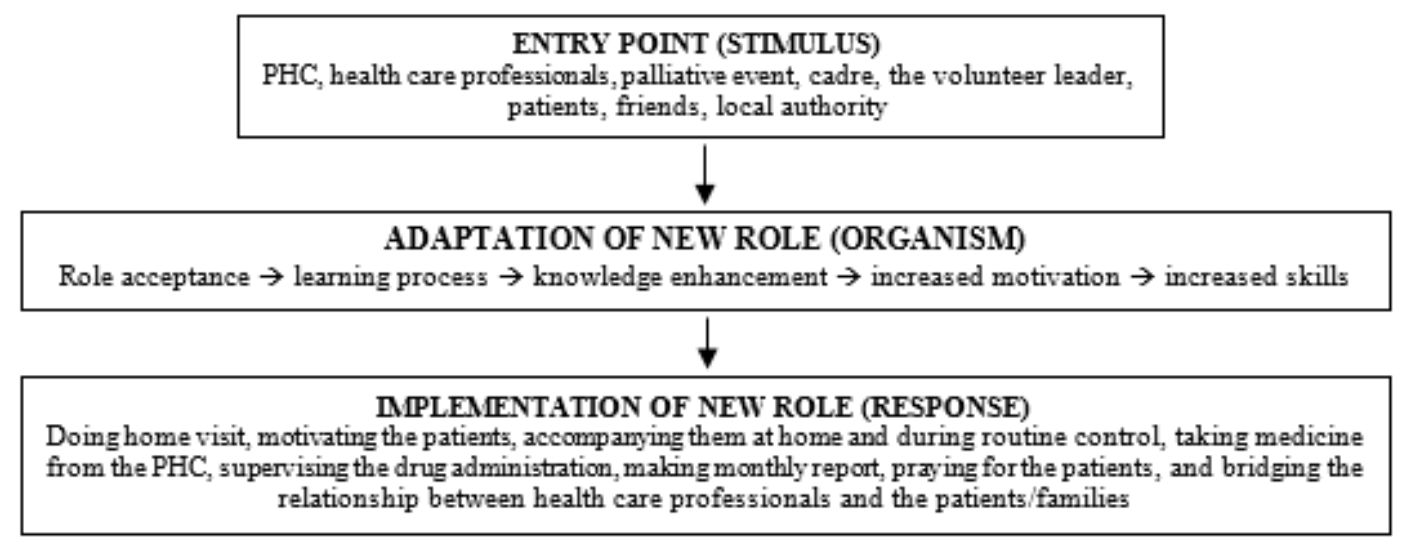

Figure 1. The steps of becoming a palliative volunteer

Simon developed a descriptive model based on the assumption that a decision maker is someone who sees problems rationally in making a workable solution based on information he got. There are seven steps (seven jumps) of decision making in the descriptive model, namely: a) Setting acceptable goals. b) Outlining subjective perceptions of the problem. c) Identifying acceptable alternatives. d) Evaluating each alternative. e) Selecting alternatives. f) Implementing decisions, and g) Evaluation [41].

Based on Figure 2, it appears that there is a little difference with the seven steps proposed by Simon. To illustrate the stage of decision making to become a palliative volunteer as outlined in Figure 2, researcher modified Skinner's behavioral theory with Simon's decision making theory based on interview results. Figure 2 showed that the process of decision making starts from exposure towards certain stimulus which added some new information to individual and then she tends to bring it into thought and feeling. Influenced by external support mainly from family and the persuasion from a respected person then individual begin to form positive attitude and internal motivation. By these driving forces, individual has initiative and encouragement to respond. In the end, he/she make a decision useful for taking action.

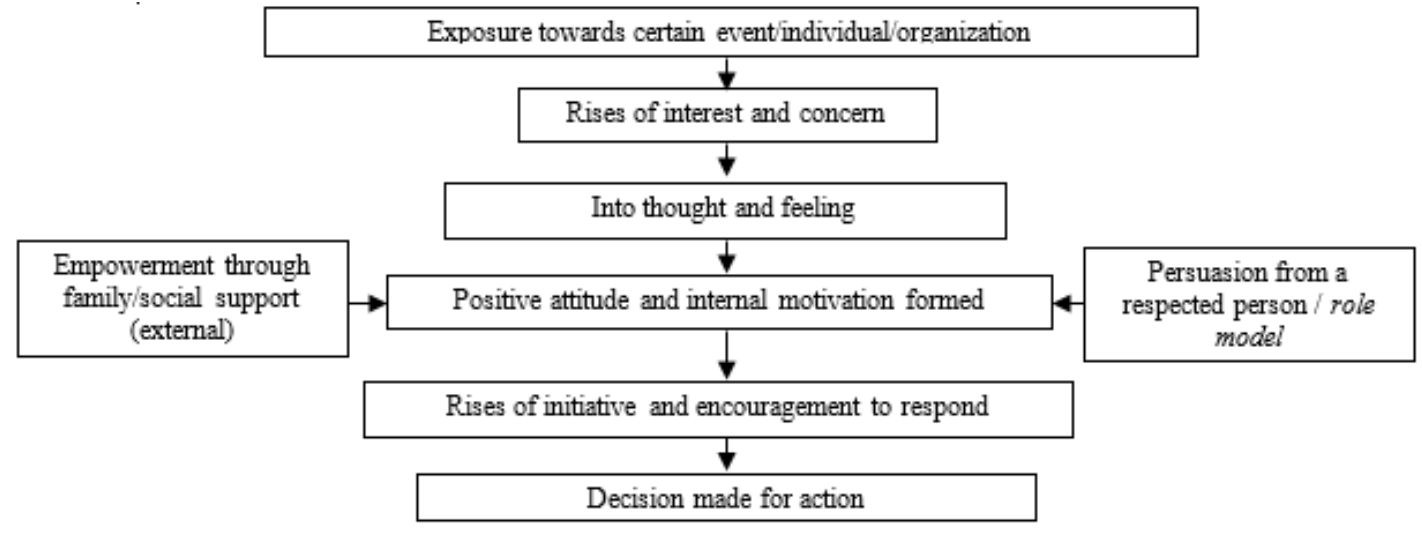

Figure 2. The decision making process of being a palliative volunteer

\subsection{Volunteer education program / training}

Results showed that $46.15 \%$ participants reported the knowledge enhancement they got after joining a volunteer training was how to do a proper home visit. Other than that were how to interact with other volunteer, how to interact with the patients, disease concept, palliative concept, patient's condition, and cancer wound. Below are few statements supporting the study findings.

When I joined the volunteer training I got knowledge about how to visit a patient at home or hospital. I got various experiences because I visited patients with different types of cancer. (I.01)

When I joined the volunteer training, I was directly asked for practice in the field by the instructor. In group, I visited a patient with advanced stage of cancer at home. I was so shock and terrified when I saw the 
patient's condition with my own eyes for the first time, and listened to her sufferings. I enhanced so much knowledge. I realized that as human being we should help each other indeed. (I.02)

The experience I got when I joined the volunteer training was at day 2 and 3 of training I was invited to join a home care activity, then I realized that however the patient's condition, a volunteer should not be picky about who is her patient and in whatever condition she is. (I.10)

After 3 days of training, I was asked to visit a patient, accidentally I visited a patient with great condition, in Rangkah, and I thought ohh this is the way how to visit a patient at home. (I.11)

Education is the addition of one's knowledge and abilities through instructional techniques, with a view to remember real facts, by giving encouragement to self-direction, actively providing new information or ideas (Craven \& Hirnle, 1996) [42]. Education is a series of efforts aimed at influencing others, ranging from individuals, groups, families and communities to the implementation of behavior [Setiawati, 2008]. So, education is a process of planned behavior change in individual, group or community to be more independent in achieving goals. In nursing, education is an independent form of nursing intervention to help clients, individuals, groups, and communities solve their health problems through learning activities, in which nurse act as educators [42].

Once accepted in recruitment, palliative volunteers are introduced to the principles of palliative care and to their role as volunteers. Emphasis is placed on protecting patients' privacy, developing interpersonal skills, and the need to coordinate all patient activities with the heath care professionals. Training sessions are conducted on psychosocial issues in end of life care, basic nursing care, and the use of alternative pain relieving modalities [43]. This study finding was supported by a study towards nine palliative volunteers in England. They found that the initial workshop/training for volunteers was really important for them to improve understanding and confidence to approach public [38]. The community nurse needs to ensure recruitment materials are explicit about the expectations on volunteers, and to explore ways of gauging whether volunteers are confident in the approach being taken to public engagement prior to commencing volunteering activities. Continuous training is needed to develop an understanding of the demographic and activities of the environment in which volunteers are based. This study also supported by another study towards nine volunteers in Norway. The findings showed that it was crucial to possess knowledge and life experience, as well as a clarified role, and volunteers stressed the importance of being followed up by a mentor. A coordinator in palliative care is especially suitable for training and supporting the volunteers [44].

The volunteer training program conducted by Dr. Soetomo public hospital of Surabaya usually begins with presentations of palliative concept, concept of total suffering, therapeutic communication, communication technique in breaking bad news, patient's needs, psychosocial and spiritual support, etc., followed by home visit to one or some patients, followed up with reflection and discussion session. Volunteer training is important for new volunteers to join before implementing the new role as palliative volunteer to develop the same perceptions between volunteers and health professionals. Nevertheless, some study participants claimed to have never attended any volunteer training, even though it has been more than one year being a volunteer. Learning process was done based on their interaction with fellow volunteers, mentors from PHC, and when interacting with patients/families during home visit. These participants still want to attend the volunteer training program, but whether Dr. Soetomo public hospital or Rangkah PHC do not provide any volunteer training at the moment. There are needs of good cooperation between agencies, such as hospital, PHC, local government, and educational institution to realize this desire.

\subsection{The duties and obligations of volunteers}

Majority of participants reported that their main duty as palliative volunteer is doing home visit $(69.23 \%)$. Other duty and obligations are motivating and accompanying the patients, taking medicine from the PHC and/or taking the patients to routine check up at the PHC, supervising the drug administration, making monthly report, praying for the patients, and bridging the relationship between health care professional and the patients/families. Below are few statements supporting the study findings.

I thought whether this duty is hard or easy for the volunteer, it is based on our attitude. As for me, as long as

I am being a volunteer, I have never felt that my job was hard because I did it in happiness. My job before any palliative event held is doing home visit or home care, pick the patients and ask them to come to join the event, after that I bring them back home, motivating them, and something similar to that. (I.04)

I thought that volunteer's job is not hard. We just take the medicines or milk from the PHC, accompany them to routine check-up in the PHC once a week. The other duty is every month we visit the patients at home routinely, especially when they cannot come to the PHC or their condition is not good. We usually weigh the patient, measure their blood pressure, and give them milk from the PHC. (I.08) 
Volunteer's duty is not hard. We should only visit the patients at home, or giving home care, motivate them so that they visit the PHC or hospital routinely for checking-up or taking the medicine. As a volunteer, we have a duty at least once a month we should visit one patient at home. (I.09)

Duty is an obligation that must be done, the job that is the responsibility, the command to do something to achieve a goal. The main task as a unity of work or activity is the main and routine duty done by employees in an organization that provides an overview of the scope or complexity of office or organization in order to achieve certain goals [45]. Liability is a responsibility or legal/moral obligation. Obligation also means a task or an action to be performed as part of a job [46].

The role of palliative volunteer was distinctive and naturally social. Volunteers themselves see their role as flexible, informal, and sometimes peripheral. The volunteer may act as a mediator between the patient and the health care staff, may take on temporary surrogate family-type relationship roles, and may also take on some of the characteristics of a paid professional [47]. A study towards seven volunteers who managed 18 patients showed that clients and family rated the volunteer service as highly important to their care because of how the volunteer helped them to make the difficult experiences of aging and advanced chronic illness more livable; significant benefits cited by clients were making good decisions for both now and in the future, having a surrogate social safety net, supporting engagement with life, and ultimately transforming the experience of living with illness [48]. Trained and supported volunteers among seriously ill or dying people within the realm of community health care services play an independent and important role in the palliative care team [44]. Their role is shaped to a community context where dying is not a private medical event, and where care is offered as a natural expression of the interdependence and reciprocity [16]. Volunteers share common beliefs, values, and goals that have been built around a culture of caring for the dying [49]. Despite limited statistical evidence, end of life volunteers clearly indicates that considerable potential benefit can be derived from them, with their efforts benefiting dying persons, their families, paid end of life staff, and themselves [50]. Clinicians can confidently refer to volunteer services at the end of life [51]. Volunteers can make the last phase of life less stressful for family caregiver by offering practical and emotional support, but every volunteer support should be concluded with a closing contact [52].

Volunteerism is a global phenomenon. Since the beginning of human civilization, the most basic humanitarian value is to help others, learn together and actively participate in the community. The duties and obligations of volunteers emerged as a direct impact of the profession/job/new role involved which is to be a palliative volunteer. Perceptions of volunteer's duty arise as a result of exposure to the learning process provided to potential volunteers through training activities or from interaction between volunteers and the patients/families or health care professionals. Palliative volunteers are an extension of health professionals in the PHC who serve as moderator or bridge the relationship between health professional and the patients/families. Based on participant's expression according to interview results, we can see that the volunteer's perception of duties and obligations is not only includes aspects of hard skills, but also soft skills.

\section{CONCLUSION}

The initial perception about the volunteer's job is to help and motivate the patient. The first impression is felt sorry for the patient. The initial desire to become a palliative volunteer comes from a close person who has cancer or appears from self/heart call. The vision and mission to be a volunteer is to help others and motivate the patients. The main reason to persistently be a volunteer despite all obstacles and limitations is the desire and passion to help others. The knowledge gained during the volunteer training is the way to do proper home visit. The duty and obligation mostly is to do home visit. The major driving force that stimulates the decision to become a volunteer is the desire to help others. The origin of social support is mostly from the family itself. The entry point that influences the decision to become a volunteer is information gained from the PHC officers. Stimulus is the entry point of information about palliative (could be individual or event), organism is the new role adaptation that occurs in self through various internal processes, and response is the new role implementation. The model of decision-making applied is the descriptive model. This model is applicable because the stage of decision-making process was based on incomplete information from various types of entry point. Steps of decision making process to become a palliative volunteer are: a) The addition of new information or knowledge enhancement due to exposure to other person or certain event. b) The emergence of interest/attention from within the individual. c) It become the material of thought and affect the individual feelings. d) Coupled with external persuasion from a respected person/role model and external support from the family/society then positive attitude and internal motivation arises. e) The urge to respond from within the individual, and f) The decision is made for actions. Further research is expected to examine the factors that influence the decision making to become palliative volunteers in the layman who has attended the volunteer training, both of which ultimately decide to become a volunteer and the one who is not. PHC officers are expected to maintain its function as a health information 
provider and the mentor/supervisor of volunteerism activities to the layman to increase their interest and maintain the recruitment of volunteers. They are also expected to give more attentions to the inactive volunteer, for empowering and supporting them.

\section{ACKNOWLEDGEMENTS}

This study was funded and supported for publication by Faculty of Nursing, Widya Mandala Catholic University Surabaya.

\section{REFERENCES}

[1] S. Tejawinata, "Surabaya, the City of Palliative: Its Image and Charm (in Bahasa Indonesia)," 2012. Surabaya: Airlangga University Press.

[2] S. Payne, J. Seymour, C. Ingleton, "Palliative Care Nursing: Principles and Evidence for Practice," 2004. England: Open University Press.

[3] A. S. Hoara, "A Realistic Vision of the Practical and Social Needs of People with Terminal Diseases," Revista de Asistenţă Socială, vol. 17, no. 3, pp. 143-149, 2018.

[4] J. Stjernswärd, "Palliative Care: The Public Health Strategy," Journal of Public Health Policy, vol. 28, no. 1, pp. 42-55, 2007.

[5] S. O. Choi, S. N. Kim, S. H. Shin, J. S. Ryu, J. W. Baik, J. R. Kim, N. H. Kim, "Evaluation of Outcomes of The Busan Community-based Palliative Care Project in Korea," Asian Nursing Research, vol. 12, pp. 286-292, 2018.

[6] A. Azeez, "Integrated Practice of Social Work Methods: Prospects of Social Work Intervention through Community Palliative Care," Social Work Chronicle, vol. 2, no. 1, pp. 1-13, 2013.

[7] R. S. U. Yusuf, "Interaction between Volunteers and Palliative Patients (Study of the Forms of Interaction between Volunteers and Palliative Patients in Advanced Accompaniment of Palliative Care for Cancer in Public Hospital of. Dr. Soetomo Surabaya) [in Bahasa Indonesia]," Jurnal Sosial dan Politik, vol. 2, no. 2, pp. 1-19, 2013.

[8] J. E. Baugher, "Pathways through Grief to Hospice Volunteering," Qual Sociol, vol. 38, pp. 305-326, 2015.

[9] B. Andersson, J. Ohlen, "Being A Hospice Volunteer," Palliative Medicine, vol. 19, pp. 602-609, 2005.

[10] R. Burbeck, J. Low, E. L. Sampson, R. Bravery, M. Hill, S. Morris, N. Ockenden, S. Payne, B. Candy, "Volunteers in Specialist Palliative Care: A Survey of Adult Services in the United Kingdom," Journal of Palliative Medicine, vol. 17, no. 5, pp. 568-574, 2014.

[11] L. E. Kuykendall Jr., "The Opportune Time: The Role of Hospice Volunteers in Helping Patients Deal with Guilt, Regret and Related Spiritual Issues at Ridge Valley Hospice," Dissertation, 2016. Pennsylvania: Lancaster Theological Seminary.

[12] S. M. Lorbach, "Recruitment, Retention, and Bumout of Hospice: Interdisciplinary Team Professionals and Volunteers," Dissertation, 2003. South Carolina: Walden University.

[13] J. H. Watts, "The Place of Volunteering in Palliative Care," Contemporary and Innovative Practice in Palliative Care, 2012. Retrieved from: Available from: http://www.intechopen.com/books/contemporary-and-innovativepractice-in-palliative-care/the-place-ofvolunteering-in-palliative-care

[14] E. Hanley, "The Role of Home Care in Palliative Care Services," Care Management Journals, vol. 5, no. 3, pp. 151-157, 2004.

[15] M. McKee, M. L. Kelley, M. Guirguis-Younger, "So No One Dies Alone: A Study Of Hospice Volunteering With Rural Seniors," Journal of Palliative Care, vol. 23, no. 3, pp. 163-172, 2007.

[16] M. McKee, M. L. Kelley, M. Guirguis-Younger, M. MacLean, S. Nadin, "It Takes A Whole Community: The Contribution of Rural Hospice Volunteers to Whole-Person Palliative Care," Journal of Palliative Care, vol. 26, no. 2, pp. 103-111, 2010.

[17] M. V. Brown, "The Stresses and Coping Skills of Hospice Volunteers," Dissertation, 2007. Utah: The University of Utah.

[18] B. A. Jack, J. Hirton, J. Birakurataki, A. Merriman, “'A bridge to the hospice': The impact of a Community Volunteer Programme in Uganda," Palliative Medicine, vol. 25, no. 7, pp. 706-715, 2011.

[19] H. J. S. Speziale, D. R. Carpenter, "Qualitative Research in Nursing: Advancing the Humanictic Imperative," $3^{\text {rd }}$ Edition, 2003. Philadelphia: Lippincott Williams \& Wilkins.

[20] J. Rakhmat, “Communication Psychology (in Bahasa Indonesia),” Revised Edition, 2008. Bandung: PT. Remaja Rosdakarya.

[21] M. Thoha, "Leadership in Management (in Bahasa Indonesia)," 2004. Jakarta: PT. Raja Grafindo Persada.

[22] Y. S. F. Susilowati, "The Influence of Accountancy Student's Perception and Interest on Public Accountant Profession towards Their Career Choice as A Public Accountant in Students of Accountancy Major in Semarang Public University (in Bahasa Indonesia), " 2010. Semarang: Universitas Negeri Semarang.

[23] M. Ikbal, "The Influence of Motivation towards Accountancy Student's Interest to Pursue the Professional Degree of Accountant," Bachelor Thesis, 2011. Semarang: Universitas Diponegoro.

[24] L. G. Schiffman, L. L. Kanuk, “Consumer Behavior,” 2000. New Jersey: Prentice Hall.

[25] Sardiman, "Interaction and Motivation on Teaching and Learning (in Bahasa Indonesia)," 2010. Jakarta: PT. Raja Grafindo Persada.

[26] O. Akintola, "What Motivates People to Volunteer? The Case of Volunteer AIDS Caregivers in Faith-based Organizations in KwaZulu-Natal, South Africa," Health Policy and Planning, vol. 26, pp. 53-62, 2010. 
[27] K. L. Fontana, "Mindfulness and Compassion: A Phenomenological Study of Hospice Dementia Care Volunteers," Dissertation, 2019. Arizona: Grand Canyon University.

[28] S. Claxton-Oldfield, J. Jefferies, C. Fawcett, L. Wasylkiw, J. Claxton-Oldfield, "Palliative Care Volunteers: Why Do They Do It?," Journal of Palliative Care, vol. 20, no. 2, pp. 78-84, 2004.

[29] D. Wibisono, "Working Performance Management: Concept, Design, and Company Technique (in Bahasa Indonesia)," 2006. Jakarta: Erlangga.

[30] Y. Tibi-Levy, M. Bungener, "Volunteering in Palliative Care in France: "A Tough Job"; Patient, Family, Caregiver, and Volunteer Perspectives," Highlights on Several Underestimated Topics in Palliative Care, pp. 55-87. Retrieved from: http://dx.doi.org/10.5772/intechopen.69754

[31] S. Notoatmodjo, "Health Education and Behavior (in Bahasa Indonesia)," 2003. Jakarta: Rineka Cipta.

[32] S. Notoatmodjo, "Health Promotion: Theory and Application (in Bahasa Indonesia)," 2005. Jakarta: Rineka Cipta.

[33] S. Hamid, "Nursing Care Plan of Mental Health (in Bahasa Indonesia)," 2011. Jakarta: EGC.

[34] Taylor, "Sosial Psychology,” 2006. New Jersey: Pearson Inc.

[35] Y. E. Soetikno, "The Influence of Social Support towards Self-care in Diabetic People in Diabetes Mellitus Club, District of Cepu, Regency of Blora, Province of Central Java (in Bahasa Indonesia)," Bachelor Thesis, 2017. Surabaya: Widya Mandala Catholic University Surabaya.

[36] S. Vanderstichelen, J. Cohen, Y. Van Wesemael, L. Deliens, K. Chambaere, "Perspectives on VolunteerProfessional Collaboration in Palliative Care: A Qualitative Study Among Volunteers, Patients, Family Carers and Healthcare Professionals (in-press: accepted manuscript)," Journal of Pain and Symptom Management, 2019. Retrieved from: https://doi.org/10.1016/j.jpainsymman.2019.04.016

[37] A. MacLeod, M. W. Skinner, E. Low, "Supporting Hospice Volunteers and Caregivers through Community-based Participatory Research," Health and Social Care in The Community, vol. 20, no. 2, pp. 190-198, 2011.

[38] M. J. Allsop, L. E. Ziegler, A. Kelly, S. Pavitt, M. I. Bennett, "Hospice Volunteers as Facilitators of Public Engagement in Palliative Care Priority Setting Research," Palliative Medicine, vol. 29, no. 8, pp. 762-763, 2015.

[39] D. Whittall, S. Lee, M. O'Connor, "Factors Affecting Rural Volunteering in Palliative Care - An Integrated Review," Australian Journal of Rural Health, vol. 24, no. 6, pp. 350-356, 2016.

[40] A. N. Sproten, C. Diener, C. J. Fiebach, C. Schwieren, "Decision Making and Age: Factors Influencing Decision Making Under Uncertainty," Journal of Behavioral and Experimental Economics, vol. 76, pp. 43-54, 2018.

[41] R. C. Swanburg, "Introduction of Leadership and Management for Clinical Nursing (in Bahasa Indonesia)," Translated Edition, 2000. Jakarta: EGC.

[42] Suliha, "Health Education in Nursing (in Bahasa Indonesia)," 2002. Jakarta: EGC.

[43] E. C. Gorospe, A. B. Bausa, "Integrating Volunteers in Palliative Care: The Philippine Experience," Journal of Palliative Care, vol. 22, no. 4, pp. 297-318, 2006.

[44] U. Söderhamn, S. Flateland, M. Fensli, R. Skaar, "To Be A Trained and Supported Volunteer in Palliative Care - A Phenomenological Study," BMC Palliative Care, vol. 16, no. 18.

[45] M. Himawan, "The Principal of Modern Organization (in Bahasa Indonesia)," 2004. Jakarta: Bina Ilmu.

[46] Oxford Living Dictionaries, "Definition of Duty in English," $2017 . \quad$ Retrieved from: https://en.oxforddictionaries.com/definition/duty

[47] R. Burbeck, B. Candy, J. Low, R. Rees, "Understanding the Role of the Volunteer in Specialist Palliative Care: A Systematic Review and Thematic Synthesis of Qualitative Studies," BMC Palliative Care, vol. 13, no. 3, pp. 2014.

[48] B. Pesut, W. Duggleby, G. Warner, K. Fassbender, E. Antifeau, B. Hooper, M. Greig, K. Sullivan, "Volunteer Navigation Partnerships: Piloting A Compassionate Community Approach to Early Palliative Care," BMC Palliative Care, vol. 17, no. 2, 2018.

[49] A. L. Watson, "Experiences of Hospice Volunteers," Master Thesis, 2001. Manitoba, Canada: University of Manitoba.

[50] D. M. Wilson, C. Justice, R. Thomas, S. Sheps, M. MacAdam, M. Brown, "End-of-life Care Volunteers: A Systematic Review of The Literature," Health Service Management Research, vol. 18, no. 4, pp. 244-257, 2005.

[51] C. Walshe, S. Dodd, M. Hill, N. Ockenden, S. Payne, N. Preston, G. P. Algorta, "How Effective are Volunteers at Supporting People in Their Last Year of Life? A Pragmatic Randomised Wait-List Trial in Palliative Care (ELSA)," BMC Medicine, vol. 14, no. 203, 2016.

[52] K. G. Luijcz, J. M. G. A. Schols, "Volunteers in Palliative Care Make a Difference," Journal of Palliative Care, vol. 25 , no. 1 , pp. 30-39, 2009. 